\title{
The Critical Role of SIRT1 in Parkinson's Disease: Mechanism and Therapeutic Considerations
}

\author{
Xuan Li1", Ya Feng,"\#, Xi-Xi Wang ${ }^{1}$, Daniel Truong ${ }^{2,3}$, Yun-Cheng Wu ${ }^{1 *}$ \\ ${ }^{1}$ Department of Neurology, Shanghai General Hospital, Shanghai Jiao Tong University School of Medicine, \\ Shanghai 200080, China. \\ ${ }^{2}$ The Truong Neurosciences Institute, Orange Coast Memorial Medical Center, Fountain Valley, CA, USA. \\ ${ }^{3}$ Department of Neurosciences and Psychiatry, University of California, Riverside, CA, USA.
}

[Received October 12, 2019; Revised February 5, 2020; Accepted February 16, 2020]

\begin{abstract}
Silence information regulator 1 (SIRT1), a member of the sirtuin family, targets histones and many non-histone proteins and participates in various physiological functions. The enzymatic activity of SIRT1 is decreased in patients with Parkinson's disease (PD), which may reduce their ability to resist neuronal damage caused by various neurotoxins. As far as we know, SIRT1 can induce autophagy by regulating autophagy related proteins such as AMP-activated protein kinase, light chain 3, mammalian target of rapamycin, and forkhead transcription factor 1. Furthermore, SIRT1 can regulate mitochondrial function and inhibit oxidative stress mainly by maintaining peroxisome proliferator-activated receptor- $\gamma$ coactivator-1 $\alpha$ (PGC-1 $\alpha$ ) in a deacetylated state and thus maintaining a constant level of PGC-1 $\alpha$. Other studies have demonstrated that SIRT1 may play a role in the pathophysiology of PD by regulating neuroinflammation. SIRT1 deacetylases nuclear factor-kappa B and thus reduces its transcriptional activity, inhibits inducible nitric oxide synthase expression, and decreases tumor necrosis factor-alpha and interleukin-6 levels. SIRT1 can also upregulate heat shock protein 70 by deacetylating heat shock factor 1 to increase the degradation of $\alpha$-synuclein oligomers. Few studies have focused on the relationship between SIRT1 single nucleotide polymorphisms and PD risk, so this topic requires further research. Based on the neuroprotective effects of SIRT1 on PD, many in vitro and in vivo experiments have demonstrated that some SIRT1 activators, notably resveratrol, have potential neuroprotective effects against dopaminergic neuronal damage caused by various neurotoxins. Thus, SIRT1 plays a critical role in PD development and might be a potential target for PD therapy.
\end{abstract}

Key words: Parkinson's disease, SIRT1, neuroprotection, STAC, therapeutic potential

Parkinson's disease (PD) is a progressive neurodegenerative disease of the central nervous system (CNS). The critical pathologic mechanism of $\mathrm{PD}$ is the progressive loss of dopaminergic (DA) neurons in the substantia nigra (SN). The cardinal clinical symptoms of PD include bradykinesia, static tremor, rigidity, and postural instability, all of which result from the reduced number of DA neurons [1,2]. The incidence of PD among women aged 60 to 69 and those over 80 is $30 / 100,000$ (men: 58/100,000) and 80/100,000 (men: 258/100,000), respectively. PD seriously affects the quality of life of patients and caregivers and imposes a heavy burden on society. Currently, there is a lack of effective therapies available for patients with PD, so the development of novel treatment strategies is urgently needed.

*Correspondence should be addressed to: Dr. Yun-Cheng Wu, Shanghai General Hospital, Shanghai Jiao Tong University School of Medicine, Shanghai, China. Email: yunchw@medmail.com.cn; drwu2006@163.com. \#These authors contributed equally to this work.

Copyright: () $2020 \mathrm{Li} \mathrm{X}$ et al. This is an open-access article distributed under the terms of the Creative Commons Attribution License, which permits unrestricted use, distribution, and reproduction in any medium, provided the original author and source are credited. 
The main neuropathological hallmarks of PD are the loss of DA neurons and the presence of Lewy bodies (LB), which mainly consist of $\alpha$-synuclein. However, the precise molecular mechanisms involved in the development and progression of PD remain unclear. Recently, it has been demonstrated that aging is a major risk factor for the development of PD. Previously, aging had been recognized as a strong disease modifier, but the pathway was not fully amenable for therapeutic manipulation until the discovery of sirtuins. Sirtuins have been shown to delay aging in various species, and thus the sirtuin family has attracted great attention over recent years. Silence information regulator 1 (SIRT1), a member of the sirtuin family, is a nicotinamide adenine dinucleotide (NAD)-dependent histone deacetylase [3]. The acetylation of histones involves the transfer of an acetyl group/acetyl group to a lysine residue/lysine residue at the $\mathrm{N}$-terminus of histones, which decreases the positive charge of histones and weakens their interaction with negatively charged DNA. Histone acetylation facilitates the binding of transcription factors and related enzymes to DNA, thus promoting gene transcription. In contrast, histone deacetylase mediates the opposite process and inhibits gene expression. Although previous studies have demonstrated that SIRT2 to SIRT7 are involved in cell survival and the stress response, these sirtuins have not been well studied. SIRT1 is involved in various physiological processes - it activates peroxisome proliferator-activated receptor- $\gamma$ coactivator- $1 \alpha$ (PGC- $1 \alpha)$ to exert anti-oxidative effects and protect mitochondria (against oxidative stress) [4], activates AMP-activated protein kinase (AMPK)-mediated autophagy to remove abnormal proteins [5], and deacetylates nuclear factorkappa B (NF-kB) to inhibit neuroinflammation [6]. SIRT1 also affects the physiological functions of normal neurons, and promotes synapse formation [7]. Recent reports have shown that SIRT1 upregulation can slow the progression of Alzheimer's disease (AD) both in vitro and in vivo [8]. Furthermore, the correlation between aging and neurodegeneration has led researchers to investigate the role of SIRT1-related pathways in PD $[9,10]$. Herein, we will discuss the critical role of SIRT1 in PD and explore the feasibility of SIRT1-related medication in the treatment of PD.

\section{Sirtuin family and their main function}

The sirtuin family comprises a group of highly conserved class III histone deacetylases. There are seven members of this family, SIRT1-SIRT7, all of which are widely distributed in cells. Each of the sirtuins has distinct enzymatic activities, sub-cellular localizations, and physiological functions. Among them, SIRT1 has the greatest homology with Sir2 in yeast. As early as the end of the last century, Sir2, a silent information regulator in yeast, was found to delay aging and prolong the lifespan of mice [11]. Similarly, mammalian SIRT1 also exhibits a lifespan-extending effect and has been extensively studied [12]. SIRT1 was initially identified as a nuclear protein, but subsequent experiments showed that it can also shuttle into the cytoplasm during neuronal differentiation, tumor progression, and apoptosis [13]. It has also been shown to regulate DNA stability, control gene expression, maintain chromosomal structure, and control cell cycle progression. SIRT2 is located in the cytoplasm and is mainly involved in cell cycle regulation. SIRT3 is expressed in the nucleus and mitochondria and plays a role in regulating cell metabolism. SIRT4 and SIRT5 are expressed in mitochondria and regulate metabolism and mitochondrial function, respectively. SIRT6 and SIRT7 are expressed in the nucleus and regulate DNA modification and rRNA transcription, respectively [14].

As mentioned above, sirtuins are class III histone deacetylases which target histones and non-histone proteins (for example, p53 and PGC-1 $\alpha$ ) and participate in many physiological functions [15]. The sub-cellular localization, enzymatic activity, and main targets of each sirtuin are shown in Table 1.

Table 1. Established biochemical and functional features of human sirtuins.

\begin{tabular}{|c|c|c|c|c|}
\hline & Function & Sub-cellular localization & Key targets & References \\
\hline SIRT1 & Deacetylase & $\begin{array}{l}\text { Nucleus } \\
\text { Cytoplasm }\end{array}$ & $\begin{array}{l}\text { p53, NF- } \kappa \text { B, IL-6, PARP- } 1, \text { PPAR- } \gamma, \text { PGC- } 1 \alpha, \\
\text { FOXO, IGF-I, AP-1, HIF- } 1 \alpha\end{array}$ & {$[16-25]$} \\
\hline SIRT2 & Deacetylase & Cytoplasm & $\alpha$-tubulin, histone $\mathrm{H} 4$ & {$[26,27]$} \\
\hline SIRT3 & Deacetylase & Mitochondria & $\begin{array}{l}\text { Acetyl-CoA acetyltransferase, } \mathrm{FOXO} 3 \text {, isocitrate } \\
\text { dehydrogenase, NADH dehydrogenase, Ku70 }\end{array}$ & {$[28-31]$} \\
\hline SIRT4 & ADP-ribosyltransferase & Mitochondria & Malonyl-CoA decarboxylase & {$[32]$} \\
\hline SIRT5 & Deacetylase & Mitochondria & Cytochrome c, carbamoyl phosphate synthase & {$[33,34]$} \\
\hline SIRT6 & $\begin{array}{l}\text { Deacetylase } \\
\text { ADP-ribosyltransferase }\end{array}$ & Nucleus & HIF-1 $\alpha, \mathrm{c}-\mathrm{Myc}$ & {$[35,36]$} \\
\hline SIRT7 & Deacetylase & Nucleus & Enzymes of nucleic acid metabolism, p53 & {$[37,38]$} \\
\hline
\end{tabular}


The pathological characteristics of PD and expression level of SIRT1

PD is characterized by two key pathological changes: 1) the dysfunction and loss of DA neurons accompanied by oxidative stress, mitochondrial dysfunction, and inflammatory or immune responses; and 2) the formation of LBs consisting of $\alpha$-synuclein, heat shock proteins (HSPs), and ubiquitin [39]. LBs exist in the central and peripheral nervous systems, in locations within the gastrointestinal system and spinal cord [40]. Interestingly, recent studies have indicated that $\alpha$-synuclein oligomers might be able to spread between cells and tissues, just like prions [41].

SIRT1 is highly expressed in neurons and glial cells in the human brain [42] and in the hippocampus and hypothalamus of the adult mouse brain [43]. The expression of SIRT1 peaks during early embryonic development and reduces over time due to aging and pathological changes [44]. In 2008, Pallàs et al. found that SIRT1 expression was significantly downregulated in rotenone-, 1-methyl-4-phenylpyridinium $\left(\mathrm{MPP}^{+}\right)$-, and kainite (KA)-treated mouse primary neurons. In contrast, SIRT1 expression was upregulated in the hippocampi of mice after KA treatment. After treatment with 1-methyl4-phenyl-1, 2, 3, 6-tetrahydropyridine (MPTP), however, SIRT1 expression in the rat midbrain was downregulated [45].

Having investigated SIRT1 expression in PD cellular and animal models, the authors then explored SIRT1 expression in brain tissue from patients with PD by measuring the protein level of SIRT1 in the cingulate gyrus. In terms of clinical symptoms, these patients had been diagnosed with PD 8 to 15 years prior and did not exhibit cognitive impairment at the time of testing. The results illustrated that there was no significant difference in the expression of SIRT1 between PD patients and healthy controls [45].

At the beginning of 2017, a more in-depth investigation was conducted [46]. This study recruited three groups of people: patients with PD; those with PD dementia (PDD); and healthy volunteers $(n=12$ per group). The investigators collected brain tissue from the participants and explored the expression of the three SIRT1 isoforms. The results indicated that the mean protein level of $120 \mathrm{kDa}$ SIRT1 in the frontal cortex was $28 \%$ lower in patients with PD than in controls $(\mathrm{P}<0.05)$, and there was no significant difference in SIRT1 level in the frontal cortex between patients with PDD and controls. The protein level of $80 \mathrm{kDa}$ SIRT1FL in the temporal cortex was $15 \%$ higher in PD patients than in controls $(\mathrm{P}<0.01)$, but there was no significant difference in SIRT1FL expression in the frontal cortex, putamen, or cerebellum between patients with PD and those with
PDD. The level of $75 \mathrm{kDa}$ SIRT1 isoform 2 in the temporal cortex was $36 \%$ higher in patients with $\mathrm{PD}$ than in controls $(\mathrm{P}<0.01)$ and $26 \%$ lower in patients with PDD than in controls $(\mathrm{P}<0.01)$. This study also found that the enzymatic activity of SIRT1 in the frontal and temporal lobes was significantly downregulated in the PD and PDD groups compared to controls, although no significant difference was seen between the two disease groups. Due to the small number of specimens, there is a lack of research on post-mortem brain tissue from PD patients. In conclusion, these two studies showed that the expression of SIRT1 differs across anatomical sites in patients with PD. However, the enzymatic activity of SIRT1 is disturbed in patients with PD, which may make these patients particularly susceptible to neurotoxin-induced neuronal damage.

\section{SIRT1 reduces $\alpha$-synuclein accumulation by regulating autophagy and heat shock factor 1 deacetylation level in PD}

It is well established that abnormal $\alpha$-synuclein aggregation in cells plays a role in the pathogenesis of PD. Preventing or reducing the production of $\alpha$-synuclein and/or promoting its elimination would delay disease progression and therefore is a promising therapeutic strategy for PD. Upregulating autophagy may have therapeutic benefits in PD. Indeed, autophagy upregulation reduces abnormal $\alpha$-synuclein accumulation in PD [47]. Autophagy plays an important role in cell tolerance to starvation, removal of misfolded proteins, delay of senescence, and maintenance of intracellular homeostasis [48]. In recent years, studies into neurodegenerative diseases have found that SIRT1 can reduce the degeneration of human nucleus pulposus cells by inducing autophagy $[49,50]$. SIRT 1 can also reduce prion protein fragment (106-126)-induced neurotoxicity by activating autophagy [51]. Our previous study found that resveratrol, a natural agonist of SIRT1, reduced the deposition of $\alpha$-synuclein in PC12 cells over-expressing $\alpha$-synuclein and increased the expression of the autophagy marker LC3-II [52]. Furthermore, we showed that the activation of SIRT1 by resveratrol led to the redistribution of LC3 from the nucleus into the cytoplasm, which was accompanied by an increase in LC3-II expression and the autophagic degradation of $\alpha$-synuclein and p62 in DA neurons. Inhibition of SIRT1 with EX527 blocked the decrease in acetylated LC3 levels, prevented its nuclear to cytoplasmic redistribution, decreased the level of LC3-II, and led to the accumulation of $\alpha$-synuclein and p62 [53].

AMPK is an extremely important energy metabolism regulator referred to as the "metabolic sensor protein" or "energy monitor" of cells, the activity of which is primarily regulated by the AMP/ATP ratio. AMPK plays 
a vital role in regulating protein degradation and autophagy [54]. SIRT1 activates AMPK's major kinase, liver kinase B1 [55]. At the same time, AMPK inhibitors significantly inhibit autophagy and decrease SIRT1 expression. The reciprocal regulation of SIRT1 and AMPK may be involved in the regulation of autophagy [56]. Our previous study showed that resveratrol induces the expression of SIRT1 and promotes AMPK phosphorylation and activation [57]. As a result, the SIRT1/AMPK pathway may be a potential target for PD therapy.

SIRT1 can also induce autophagy by regulating the tuberous sclerosis 2 (TSC2) mammalian target of rapamycin (mTOR)-ribosomal protein $\mathrm{S} 6$ kinase 1 (S6K1) pathway and promoting neuronal survival in cerebral ischemic tissue [58]. In addition, studies have reported that the deacetylation of forkhead transcription factor 1 (FOXO1) by SIRT1 plays an important role in the development of starvation-induced autophagy [59, 60]. SIRT1-mediated RelA/p65 deacetylation can also promote autophagy to some extent [61, 62]. Therefore, we speculated that SIRT1 may promote the degradation of $\alpha$ synuclein by inducing autophagy, which may have important implications for preventing or delaying the progression of PD. The studies described earlier also indicate that SIRT1 plays a key role in the regulation of autophagy through multiple pathways, although which of the known or as yet unidentified pathways is most important remains unclear.

In addition to autophagy, molecular chaperones are also involved in clearing misfolded proteins. For most proteins, molecular chaperone-mediated formation of their native conformation is one of the major posttranslational modifications. In addition to assisting in protein folding, molecular chaperones also stabilize the protein and maintain the polypeptide chain components in a loosely folded state for passing through the organelle membrane [63]. More specifically, molecular chaperones can recognize the hydrophobic surface of misfolded monomers and transfer them to the ubiquitin-proteasome system or promote chaperone-mediated autophagy. This process can reduce the cytotoxicity of misfolded proteins by preventing them from accumulating in the cytosol [64]. Molecular chaperones are regulated by heat shock transcription factors (HSFs) and other cofactors to effectively remove toxic protein monomers and oligomers and promote protein homeostasis $[65,66]$. The structure and function of HSFs are highly conserved and exhibit a high degree of homology. Among them, HSF1 is the most representative HSFs. In addition to phosphorylation, SIRT1 deacetylation can also activate HSF1 under stress conditions, thereby maintaining HSF1 in a deacetylated, DNA-binding competent state $[67,68]$. In contrast, inhibiting SIRT1 expression with small interfering RNAs inhibits the transcription of heat shock genes. Studies have shown that SIRT1 overexpression can reduce the formation of $\alpha$-synuclein aggregates [46]. However, SIRT1 does not appear to directly decrease the content of $\alpha$-synuclein oligomers. Rather, SIRT1 keeps HSF1 in a deacetylated, DNA-binding competent state, which prolongs the binding of HSF1 to the heat shock promoter of the heat shock protein 70 (Hsp70). This process enhances the transcription of the Hsp70, which enhances the viability of cultured cells exposed to heat shock and induces the degradation of $\alpha$-synuclein oligomers [69, 70].

In addition to affecting the clearance of $\alpha$-synuclein, SIRT1 can also affect the phosphorylation of $\alpha$-synuclein, which may reduce the formation of $\alpha$-synuclein aggregates. Singh et al. observed a low level of basal phosphor- $\alpha$-synuclein accumulation which was reduced slightly by SIRT1 overexpression. However, they also observed that under conditions of oxidative stress, overexpression of SIRT1WT reduced the formation of phospho- $\alpha$-synuclein aggregates and SIRT1H363Y (a catalytically inactive variant of SIRT1) showed a similar effect to control cells. Interestingly, SIRT1 was not colocalized with phospho- $\alpha$-synuclein, suggesting that the effect of SIRT1 on phospho- $\alpha$-synuclein aggregate formation is indirect and independent of deacetylase activity. Rather, this effect may be mediated via an elevation of cellular anti-oxidant defense mechanisms [46].

\section{SIRT1 regulates apoptosis in PD}

In the pathogenesis of PD, cell apoptosis is an important cause of DA neuronal loss, and this may also be the ultimate common pathway leading to the loss of DA neurons. Studies have shown that SIRT1 can reduce the damage caused by neurodegenerative diseases by regulating the apoptosis of neural cells. Consequently, targeting neuronal apoptosis may be an effective strategy for the treatment of neurodegenerative diseases.

In a previous study, resveratrol significantly reversed rotenone-induced decreases in SIRT1 expression and protein kinase B (Akt) phosphorylation and exhibited an obvious neuroprotective effect against rotenone-induced neurotoxicity. Moreover, when the SIRT1/Akt1 signaling pathway was inhibited, the neuroprotective effect of resveratrol was remarkably attenuated, which implied that SIRT1 and Akt1 could mediate neuroprotection and were potential molecular targets for intervening against rotenone-induced neurotoxicity [71]. During apoptosis, p53 interacts with members of the B-cell lymphoma 2 (Bcl-2) family, including the anti-apoptotic protein Bcl. P53 also induces Bcl-2 homologous antagonist/killer oligomerization, permeabilizes the mitochondrial 
membrane, rapidly induces the release of cytochrome $\mathrm{C}$, and activates cell apoptosis. Our previous studies showed that resveratrol protects against neurotoxicity in a SIRT1dependent manner. We demonstrated that SIRT1 targets $\mathrm{H} 3 \mathrm{~K} 9$ histone and regulates p53 gene expression at the transcriptional level, thus inhibiting p53 gene expression to enhance neuroprotection [57]. Studies by other investigators have shown that during cell stress, SIRT1 deacetylates the C-terminal residues of the main site of p53 ubiquitination, which helps block protein degradation and stabilize p53 [72]. SIRT1 can also deacetylate $\mathrm{Ku} 70$ in tumor [73, 74] and retinal cells [75] to enhance DNA repair activity and chelate $\mathrm{Bcl}-2$-associated $\mathrm{X}$ protein (Bax) in the cytoplasm to prevent apoptosis and extend cell lifespan. However, the role of the SIRT1/Ku70 pathway in the nervous system requires further elucidation.

\section{SIRT1 regulates mitochondrial function and oxidative stress in PD}

Studies have confirmed that mitochondrial dysfunction and oxidative stress play a role in the DA toxicity known to underlie PD. Brain tissue has a high oxygen metabolism rate but lacks an effective antioxidant protective mechanism to counteract this. Recent research has shown that the increase in early oxygen free radicals in PD can still enhance the activity of the striatum antioxidant enzyme system through the body's compensatory response and thus resist the damage caused by oxygen free radicals. However, as the disease progresses, the production of free radicals accelerates, and the body's compensatory response cannot resist the damage caused by oxygen free radicals. The striatal pro-oxidant and antioxidant systems fall out of balance, leading to neuronal damage and apoptosis [76]. PGC- $1 \alpha$ is a multifunctional factor that can activate many nuclear receptors and transcription factors [77]. It has been experimentally confirmed that PGC- $1 \alpha$ reduces cell apoptosis by increasing the activity and protein levels of anti-oxidant enzymes, whereas the expression of catalase (CAT), superoxide dismutase 1 (SOD1), and SOD2 in PGC-1 $\alpha$ knockout mice is significantly lower than that in normal mice [78].

The histone acetyltransferase complex can directly acetylate multiple lysine residues of PGC- $1 \alpha$, inhibiting its transcriptional activity and decreasing the antioxidative activity of PGC-1 $\alpha$ [79]. In contrast, SIRT1 activation can deacetylate PGC- $1 \alpha$ to maintain high protein levels of this factor, thereby enhancing its antioxidant activity [80]. Furthermore, the SIRT1 inhibitor nicotinamide can attenuate the anti-oxidative ability of wild-type cells but not PGC-1 $\alpha$-overexpressing cells, confirming that PGC- $1 \alpha$ acts downstream of SIRT1.
Taken together, these studies suggest that SIRT1 upregulates PGC- $1 \alpha$ expression during oxidative stress and imply that the SIRT1/PGC-1 $\alpha$ pathway may play an active role in the prevention and treatment of PD.

\section{SIRT1 regulates inflammatory responses in PD}

Studies have confirmed that microglial cells can be switched from a resting state to an activated state [81]. A recent study indicated that microglial activation can affect DA neurons by enhancing oxidative stress and promoting the production of proinflammatory cytokines that initiate an inflammatory cascade [82]. Some scholars believe that neuroinflammation damages the DA neurons of the SN and promotes their apoptosis in patients with PD [83]. In contrast, other studies have shown that neuroinflammation has a protective effect on the CNS [84]. Whether neuroinflammation is the main cause of DA neuronal loss or a secondary response to neuronal apoptosis remains to be elucidated. Nevertheless, there is no doubt that neuroinflammation plays a role in the progression of PD [85]. Recent studies have revealed that the beneficial effect of SIRT1 on PD is due in part to its ability to suppress the transcriptional ability of nuclear factor-kappa B (NF-kB) via deacetylation [86]. It was shown that resveratrol suppressed the lipopolysaccharide (LPS)-induced degradation of $\mathrm{I} \kappa \mathrm{B}$, expression of inducible nitric oxide synthase, and phosphorylation of p38 mitogen-activated protein kinases in N9 microglial cells. Lending further support to these findings, SIRT1 deficiency in microglia contributes to age-related cognitive decline and neurodegeneration via epigenetic regulation of interleukin-1 $\beta$ [87]. Furthermore, Xiu Li Bi and colleagues demonstrated that resveratrol potently inhibited the production of tumor necrosis factor-alpha and nitric oxide by LPS-activated microglial cells [88]. Taken together, these results demonstrate that SIRT1 suppresses the proinflammatory responses of microglia, suggesting that SIRT1 may participate in the progression of PD by regulating neuroinflammation.

\section{The relationship between SIRT1 single nucleotide polymorphisms and PD}

Single nucleotide polymorphisms (SNPs) are the most common type of genetic polymorphism. SNPs can be used to locate disease susceptibility genes, assess disease risk, and prognosticate long-term outcome. Based on the neuroprotective effects of SIRT1 in PD, numerous studies have been conducted to investigate whether SIRT1 SNPs are associated with an increased risk of PD. Zhang et al. showed that three novel hybrid sequence variants located in the promoter region were identified among 97 patients with sporadic PD in northern China (g.69644133C>G, 
g.69644213G>A, and g.69644351G>A) [89], whereas these heterozygous sequence variants were not observed in the control population. Therefore, they speculated that these three variants may alter the transcription factor locus of the SIRT1 gene promoter, reduce SIRT1 expression, and increase the risk of sporadic PD. Another study included 326 PD patients and 371 controls from southern Spain, and genotyped 41 SNPs in sirtuin genes in order to determine whether they were related to PD risk. These SNPs included Tag SNPs, coding non-synonymous SNPs, and SNPs affecting the activity of microRNA binding sites. No relationship was identified between these SNPs and PD risk. Their data also indicate that variations in sirtuin genes do not affect PD risk, at least in the population analyzed in their study [90]. One Chinese casecontrol study, which included 259 patients with PD and 253 healthy controls, demonstrated that the SIRT1 rs7895833 GG mutant genotype was associated with more severe anxiety symptoms (assessed using the Hamilton Anxiety Scale) [91]. SIRT1 SNPs are associated with many age-related conditions including $\mathrm{AD}$ [92] and longevity [93]. It is expected that future studies will explore the basis of the interaction between SIRT1 SNPs and PD risk.

\section{SIRT1 activators and their neuroprotective effects in PD}

Resveratrol, an activator of SIRT1, is a polyphenolic compound found in a variety of plants and drugs such as grape skin and peanuts. As a multi-targeted, pleiotropic, and natural compound, resveratrol can enter the brain through the blood-brain barrier [94] and has been found to exert protective effects in a variety of neurodegenerative diseases, including PD [95]. In vitro, resveratrol can reduce the damage and toxic effects of oxidative stress and $\alpha$-synuclein (A30P) aggregation in SK-N-BE neuroblastoma cells [96]. It can also reduce DA-induced oxidative stress in SH-SY5Y cells [97] and alleviate the apoptosis of cerebellar granule cells induced by $\mathrm{MPP}^{+}[98,99]$. Resveratrol attenuates $\mathrm{MPP}^{+}$-induced PC12 cell death through its regulation of the pro-apoptotic factor $\mathrm{Bax}$ and anti-apoptotic factor $\mathrm{Bcl}-2$ [99]. Resveratrol can induce autophagy by promoting the expression of heme oxygenase-1, which in turn reduces rotenone-induced PC12 apoptosis [100]. Studies using animal models of PD have shown that resveratrol enhances the activity of anti-oxidant enzymes such as glutathione peroxidase, glutathione reductase, and CAT. At the same time, it downregulates the activity of thiobarbituric acid reactive substances, protein carbonyl, and phospholipase 2 . Together, these processes prevent the loss of DA neurons in the MPTP mouse model of PD [101-103].
Resveratrol also has a protective effect on 6hydroxydopamine hydrobromide (6-OHDA)-induced PD rat models through its anti-oxidant and anti-inflammatory effects [104]. In addition, the analysis of fibroblasts from two patients with early-onset PD carrying two mutations in the PARK2 gene revealed that resveratrol regulates the downstream target of PGC- $1 \alpha$, reduces oxidative stress, promotes mitochondrial biosynthesis, and regulates energy metabolism [105]. Our previous studies showed that resveratrol can reduce the apoptosis of SH-SY5Y cells induced by rotenone [57] and the deposition of $\alpha$ synuclein in $\alpha$-synuclein-overexpressing PC12 cells [52]. Furthermore, resveratrol ameliorated motor deficits and pathological changes in MPTP-treated mice, whereas inhibition of SIRT1 by EX527 partially abolished the rescue effects of resveratrol. Therefore, exploring the neuroprotective effects of resveratrol and its underlying mechanisms may provide an experimental basis for the prevention and treatment of PD.

Despite recent data demonstrating the neuroprotective effects of resveratrol, there is still some controversy over whether it could be used as an effective pharmacotherapy. It should be noted that it is unclear how much dietary resveratrol is required to achieve beneficial effects. Various resveratrol concentrations have been reported in in vitro and in vivo studies. Ultimately, $450 \mathrm{mg} /$ day of resveratrol has been deemed safe for a 60 $\mathrm{kg}$ individual [106]. However, it is important to note that the health benefits of resveratrol are not due to its antioxidant activity alone, but also its anti-inflammatory and neuroprotective properties. Further studies assessing other routes of administration or pharmaceutical formulations (i.e., nanoencapsulation) are required to improve the concentration of resveratrol in target tissues and allow this drug to exert its biological effects in PD.

The design of novel compounds that can directly activate SIRT1 and improve its bioavailability remains a critical goal in the field of neuropharmacology. The first sirtuin-activating compounds (STACs) were discovered in 2003. Since then, high-throughput screening and medicinal chemistry efforts have identified more than 14,000 STACs from a dozen chemical classes, including plant-derived STACs such as stilbenes (resveratrol), chalcones (butein), and flavones (quercetin) [107] and synthetic STACs including imidazothiazoles (SRT1720) [108], thiazolopyridines (STAC-2), benzimidazoles (STAC-5), and bridged ureas (STAC-9).

Many studies have also focused on the role of phenolic compounds in PD. Among the polyphenol classes, stilbenes have been shown to exert a broad range of beneficial effects [109]. Stilbenes are ubiquitous in grapes and its related products [110]. A previous study investigated the effects of three stilbenes extracted from vine stalks - a monomer (piceatannol), a dimer 
(ampelopsin A), and a tetramer (isohopeaphenol) - on $\alpha$ synuclein fibrillation. This study demonstrated that piceatannol could inhibit $\alpha$-synuclein fibrillation by forming soluble, non-toxic $\alpha$-synuclein/polyphenol oligomers in neuronal PC12 cells [111].

Dozens of STACs have been tested in animal models of type 2 diabetes, aging, neurodegeneration, osteoporosis, infection, fatty liver disease, and atherosclerosis [108, 112-116]. To date, synthetic STACs are in their fifth generation, and have an in vitro potency $>1000$ times higher than that of resveratrol. Therefore, new synthetic drugs show great promise in the treatment of PD, such as some new small molecule SIRT1 activators (SRT1720, SRT2014, SRT3025, SRT2183, and SRT1460). In addition to these SIRT1 activators, a recent study using optimized high throughput screening identified E6155, a piperazine 1, 4-diamide compound, as a new small molecule activator of SIRT1. Ultimately, the authors of this study concluded that E6155 could be a promising candidate for treating insulin resistance and diabetes [117]. The role of these compounds in PD is worthy of further exploration. Sirtuin activators and their clinical applications are listed in Table 2.

Table 2. Sirtuin activators and their clinical applications (except Parkinson's disease).

\begin{tabular}{lll}
\hline Compound name & Clinical applications & References \\
\hline Resveratrol & $\begin{array}{l}\text { Cardiovascular disease, atherosclerosis, } \\
\text { diabetes, sleep disorders, AD, cancer }\end{array}$ & $\begin{array}{l}\text { Zordoky et al. [118], Agarwal et al. [119], } \\
\text { Seyyedebrahimi et al. [120], Pennisi et al. [121], } \\
\text { Moussa et al. [122], Banaszewska et al. [123] }\end{array}$ \\
SRT2104, & $\begin{array}{l}\text { Type 2 diabetes, ulcerative } \\
\text { colitis, psoriasis, effect on lipid parameters }\end{array}$ & $\begin{array}{l}\text { Baksi et al. [124], Sands et al. [125], Krueger et al. } \\
\text { [126], Venkatasubramanian et al.[127] }\end{array}$ \\
SRT2183, & & \\
SRT1460 & & \\
E6155 & Diabetes & Liu et al. [89] \\
P7C3 and its analog & AD, ALS, traumatic brain injury, acute liver & Voorhees et al.[128], Tesla et al.[129], Blaya et al. \\
& injury, ischemic stroke, optic nerve injury & [130], Zhang et al. [131],Oku et al. [132], Wang et al. \\
& & \\
\hline
\end{tabular}

Abbreviations: AD - Alzheimer's disease, ALS - amyotrophic lateral sclerosis

NAD-boosting molecules constitute a newer class of STACs [134]. Since 2003, studies have shown that recycling NAD from nicotinamide by upregulating the NAD remediation pathway can mimic calorie restriction and extend the lifespan of yeast [135]. Stress and calorie restriction can activate the PNC1 gene, which encodes NAD and regulates the rate-limiting steps of the NAD salvage pathway in yeast, thus increasing the activity of Sir2 [136]. In mammals, the homolog of PNC1 is nicotinamide phosphoribosyl transferase (NAMPT). As a major precursor of NAD, nicotine is first catalyzed by NAMPT to nicotinamide mononucleotide, and is then converted to NAD [137]. NAMPT acts as a rate-limiting enzyme. Therefore, the enzymes that regulate NAD levels, such as CD38, CD157, and NAMPT, may also be potential therapeutic targets worth exploring. In a previous study, NAMPT markedly protected PC12 cells against 6-OHDA-induced oxidative stress-associated cell death. The protective effect of NAMPT may be attributed to increases in glutathione levels and SOD activity and a reduction of NAD levels, all of which are consequences of increased SIRT1 activity [138]. NAMPT, NAD, and SIRT1 may therefore play a crucial role in PD and other neurodegenerative disorders. A recent study indicated that P7C3, a compound which exerts its function by allosterically activating NAMPT [139], also blocks MPTP-mediated cell death in the SN of adult mice. Doseresponse studies showed that the P7C3 analog P7C3A20 inhibits cell death with even greater potency and efficacy. These researchers further demonstrated that the hippocampal pro-neurogenic efficacy of eight additional analogs of P7C3 correlates with their protective effects against MPTP-mediated neurotoxicity [140].

Naturally occurring STACs such as resveratrol and chemically unrelated synthetic STACs activate SIRT1 in vitro by lowering its peptide Michaelis constant $\left(\mathrm{K}_{\mathrm{M}}\right)$ and produce pharmacological changes consistent with SIRT1 activation $[108,141]$. However, the theory that STACs are direct SIRT1 activators has been widely debated. As reported by Hubbard et al., resveratrol and synthetic STACs (SRT1720 and SRT2014) increased mitochondrial mass and ATP content in wild-type, but not SIRT1 knockout myoblasts. In myoblasts expressing the E230K SIRT1 mutation, the effects of STACs on mitochondrial mass and ATP levels were also blocked [142]. However, Pacholec et al. demonstrated that SRT1720, SRT2183, SRT1460, and resveratrol are not direct SIRT1 activators by conducting several biochemical assays with native substrates and biophysical studies employing nuclear magnetic resonance, surface 
plasmon resonance, and isothermal titration calorimetry [143]. The broad selectivity assessment against over 100 targets including receptors, enzymes, ion channels, and transporters showed that SRT1720, SRT2183, SRT1460, and resveratrol are highly promiscuous and would not serve as useful pharmacological tools for studying SIRT1 pathways. Thus, we conclude that, to date, the evidence base from clinical studies is insufficient, contradictory, and inconclusive. We therefore recommend that further clinical trials be conducted to substantiate the neuroprotective effects of STACs and their likely mechanisms of action.

\section{Exercise-induced neuroprotection in PD may be related to SIRT1 activation}

The beneficial effects of exercise against nigral DA neuronal vulnerability and PD progression have been shown in several studies [144, 145]. Tuon et al. demonstrated that physical exercise such as treadmill and strength training promoted neuroprotection. The mechanism underlying the neuroprotective effect of exercise may involve the activation of SIRT1, which can regulate mitochondrial function and neuroinflammation via the deacetylation of NF- $\kappa B$ [146]. Therefore, the neuroprotective effects of physical exercise may be mediated by SIRT1 activation [147].

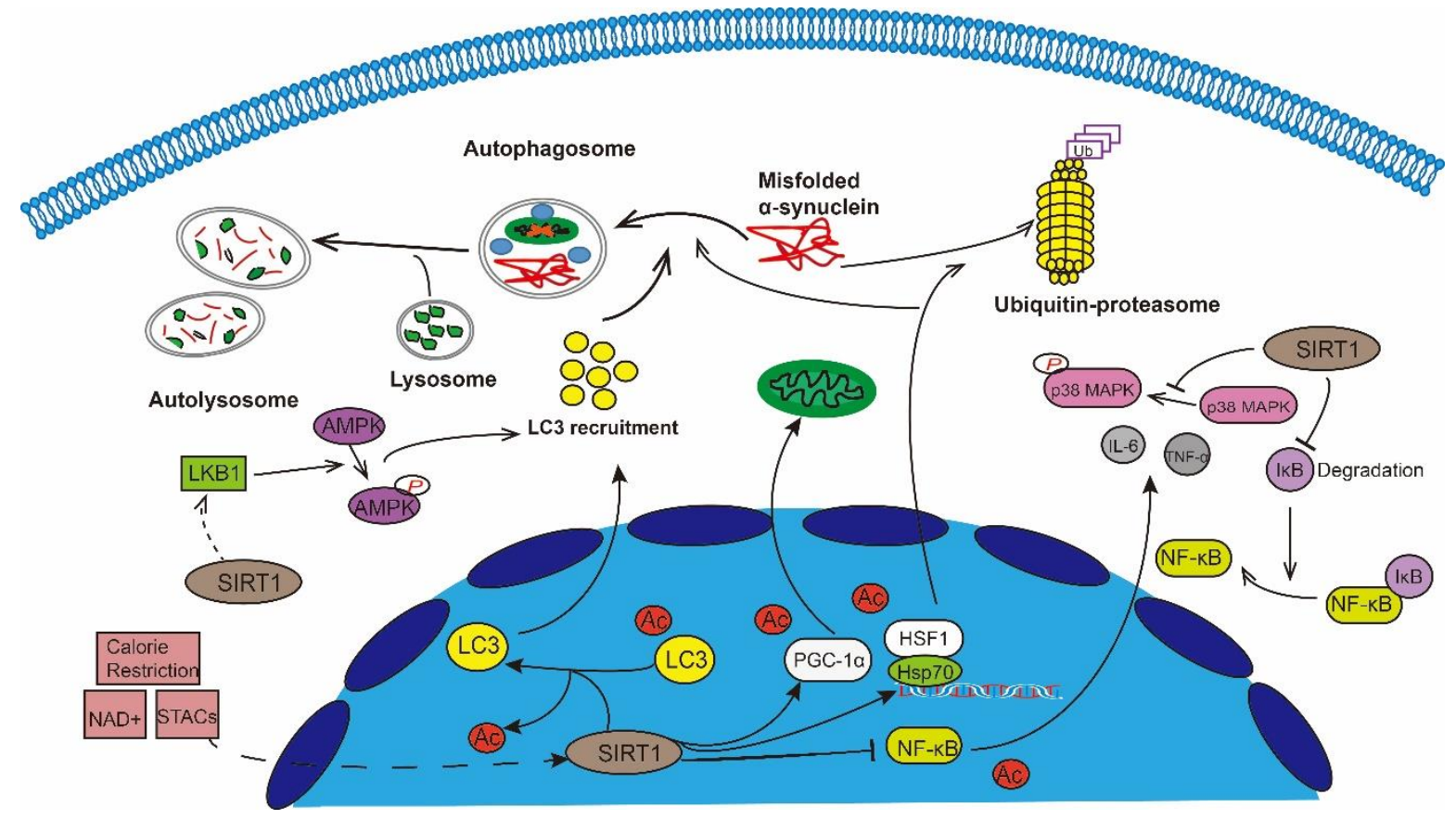

Figure 1. SIRT1 has been shown to participate in neuroprotective against PD through multiple mechanisms. SIRT1 can induce autophagy through regulating autophagy relevant proteins such as AMPK, Atg protein family, LC3, mTOR and FOXO1. Furthermore, SIRT1 can regulate mitochondrial function and oxidative stress mainly by keeping the deacetylated state of PGC- $1 \alpha$ to maintain PGC-1 $\alpha$ levels. Many experiments have demonstrated that SIRT1 may participate in the PD process through neuroinflammation. It mainly reduces NF- $\kappa$ B by deacetylating its transcriptional activity, inhibits iNOS expression, decreases TNF- $\alpha$ and IL-6 levels. SIRT1 can also up-regulate HSP70 by deacetylating HSF1 to increase the degradation of $\alpha$-Synuclein oligomers.

\section{Conclusions}

Currently, the therapeutic options available for PD are limited. The most effective treatment remains the restoration of DA neuronal function by DA supplementation. Unfortunately, however, long-term levodopa treatment is often associated with reduced efficacy and serious adverse reactions. Therefore, the identification of new therapeutic strategies is urgently needed. Aging is the major risk factor for PD, and growing evidence has shown that sirtuins are essential in delaying cellular senescence and extending organismal lifespan. SIRT1, the most extensively studied human sirtuin, is a predominantly nuclear protein that has been shown to deacetylate some non-histone targets such as p53 [57, 148], Ku70 [149, 150], peroxisome proliferatoractivated receptor- $\gamma[151,152], \mathrm{PGC}-1 \alpha, \mathrm{NF}-\kappa \mathrm{B}$, hypoxia inducible factor-1 alpha [25], and several FOXO isoforms. SIRT1 is involved in the regulation of various important cellular processes including cell proliferation, 
DNA repair, and apoptosis. SIRT1 has also been shown to play a role in the neuroprotective effects of PD through multiple mechanisms (Fig. 1), primarily by regulating mitochondrial function, autophagy, and neuroinflammation.

In addition to PD, SIRT1 has been implicated in the pathophysiology of other neurodegenerative diseases. Reduced SIRT1 levels have been observed in the parietal cortex of patients with AD and an inverse correlation has been observed between SIRT1 levels and the degree of tau protein accumulation in the advanced stages of AD in humans [153]. The overexpression of SIRT1 in HEK293T cells expressing human tau led to a reduction in acetylated tau levels, while deletion of SIRT1 resulted in tau hyperacetylation. Furthermore, a glutathione Stransferase pull-down assay showed a direct interaction between SIRT1 and tau [154]. Another neurodegenerative disease in which SIRT1 has been investigated is Huntington's disease (HD). Brain-specific knockout of SIRT1 in a mouse model of HD exacerbated the pathological features of HD. SIRT1 overexpression afforded neuroprotection against HD, and this was dependent on the deacetylation of CREB-regulated transcription coactivator 1 (TORC1) by SIRT1, an interaction which increased BDNF transcription. In the presence of the mutant HD protein, the SIRT1-TORC1 interaction was inhibited, repressing BDNF transcription [155]. In addition to providing neuroprotection against neurodegenerative diseases, the activation of SIRT1 has been shown to confer protection against cerebral ischemia [156] and metabolic diseases such as obesity [157] and type 2 diabetes [158].

In summary, regulating SIRT1 expression is a potential therapeutic strategy, but the specific molecular mechanism underlying its action requires further elucidation. Furthermore, compounds found to have therapeutic benefit in other neurodegenerative diseases, such as resveratrol and chemically unrelated synthetic STACs, may hold promise for the future of PD treatment. The potential benefit of SIRT1 agonists in the treatment of PD continues to be debated and requires further exploration. Hence, large-scale, multi-center clinical trials need to be conducted to help us obtain more accurate information.

\section{Acknowledgements}

This work was supported by grants from the National Natural Science Foundation of China (Nos. 81171205, 81371410, 81671251, and 81971185).

\section{Competing interests}

The authors declare that they have no conflict of interest.

\section{References}

[1] Chahine LM, Amara AW, Videnovic A (2017). A systematic review of the literature on disorders of sleep and wakefulness in Parkinson's disease from 2005 to 2015. Sleep Med Rev, 35:33-50.

[2] Maloney EM, Djamshidian A, O'Sullivan SS (2017). Phenomenology and epidemiology of impulsivecompulsive behaviours in Parkinson's disease, atypical Parkinsonian disorders and non-Parkinsonian populations. J Neurol Sci, 374:47-52.

[3] Johnson S, Imai SI (2018). NAD (+) biosynthesis, aging, and disease. F1000Res, 7:132.

[4] Khan SA, Sathyanarayan A, Mashek MT, Ong KT, Wollaston-Hayden EE, Mashek DG (2015). ATGLcatalyzed lipolysis regulates SIRT1 to control PGC1alpha/PPAR-alpha signaling. Diabetes, 64:418-426.

[5] Shekhar S, Yadav Y, Singh AP, Pradhan R, Desai GR, Dey $A B$, et al. (2018). Neuroprotection by ethanolic extract of Syzygium aromaticum in Alzheimer's disease like pathology via maintaining oxidative balance through SIRT1 pathway. Exp Gerontol, 110:277-283.

[6] Kauppinen A, Suuronen T, Ojala J, Kaarniranta K, Salminen A (2013). Antagonistic crosstalk between NF-kappaB and SIRT1 in the regulation of inflammation and metabolic disorders. Cell Signal, 25:1939-1948.

[7] Kupis W, Palyga J, Tomal E, Niewiadomska E (2016). The role of sirtuins in cellular homeostasis. J Physiol Biochem, 72:371-380.

[8] Corpas R, Revilla S, Ursulet S, Castro-Freire M, Kaliman P, Petegnief V, et al. (2017). SIRT1 overexpression in mouse hippocampus induces cognitive enhancement through proteostatic and neurotrophic mechanisms. Mol Neurobiol, 54:56045619.

[9] Herskovits AZ, Guarente L (2014). SIRT1 in neurodevelopment and brain senescence. Neuron, 81:471-483.

[10] Donmez G, Outeiro TF (2013). SIRT1 and SIRT2: emerging targets in neurodegeneration. EMBO Mol Med, 5:344-352.

[11] Kaeberlein M, McVey M, Guarente L (1999). The SIR2/3/4 complex and SIR2 alone promote longevity in saccharomyces cerevisiae by two different mechanisms. Genes Dev, 13:2570-2580.

[12] Satoh A, Brace CS, Rensing N, Cliften P, Wozniak DF, Herzog ED, et al. (2013). SIRT1 extends life span and delays aging in mice through the regulation of $\mathrm{Nk} 2$ homeobox 1 in the DMH and LH. Cell Metab, 18:416430.

[13] Tanno M, Sakamoto J, Miura T, Shimamoto K, Horio Y (2007). Nucleocytoplasmic shuttling of the NAD+dependent histone deacetylase SIRT1. J Biol Chem, 282:6823-6832.

Polak-Jonkisz D, Laszki-Szczạchor K, Rehan L, Pilecki W, Filipowski H, Sobieszczańska M (2013). Nephroprotective action of sirtuin 1 (SIRT1). J Physiol 
Biochem, 69:957-961.

[15] Favero G, Franceschetti L, Rodella LF, Rezzani R (2015). Sirtuins, aging, and cardiovascular risks. Age (Dordr), 37:9804.

[16] Zhao L, Liu H, Yue L, Zhang J, Li X, Wang B, et al. (2017). Melatonin attenuates early brain injury via the melatonin receptor/SIRT1/NF-kappaB signaling pathway following subarachnoid hemorrhage in mice. Mol Neurobiol, 54:1612-1621.

[17] Feng S, Li M, Zhang J, Liu S, Wang Q, Quan M, et al. (2015). Regulation of HepG2 cell apoptosis by hepatitis $\mathrm{C}$ virus (HCV) core protein via the sirt1-p53bax pathway. Virus Genes, 51:338-346.

[18] Wang WR, Li TT, Jing T, Li YX, Yang XF, He YH, et al. (2017). SIRT1 regulates the inflammatory response of vascular adventitial fibroblasts through autophagy and related signaling pathway. Cell Physiol Biochem, 41:569-582.

[19] Said RS, El-Demerdash E, Nada AS, Kamal MM (2016). Resveratrol inhibits inflammatory signaling implicated in ionizing radiation-induced premature ovarian failure through antagonistic crosstalk between silencing information regulator 1 (SIRT1) and poly(ADP-ribose) polymerase 1 (PARP-1). Biochem Pharmacol, 103:140-150.

[20] Chan SH, Chu PM, Kao CL, Cheng YH, Hung CH, Tsai KL (2016). Oleic acid activates MMPs upregulation through SIRT1/PPAR-gamma inhibition: a probable linkage between obesity and coronary arterial disease. J Biochem, 160:217-225.

[21] Zhang T, Chi Y, Ren Y, Du C, Shi Y, Li Y (2019). Resveratrol reduces oxidative stress and apoptosis in podocytes via Sir2-related enzymes, sirtuins1 (SIRT1)/peroxisome proliferator-activated receptor gamma co-activator 1alpha (PGC-1alpha) Axis. Med Sci Monit, 25:1220-1231.

[22] Wang A, Li T, An P, Yan W, Zheng H, Wang B, et al. (2017). Exendin-4 upregulates adiponectin level in adipocytes via Sirt1/Foxo-1 signaling pathway. PLoS One, 12:e0169469.

[23] Reverchon M, Rame C, Bunel A, Chen W, Froment P, Dupont J (2016). VISFATIN (NAMPT) improves in vitro IGF1-induced steroidogenesis and IGF1 receptor signaling through SIRT1 in bovine granulosa cells. Biol Reprod, 94:54.

[24] Ren JH, Tao Y, Zhang ZZ, Chen WX, Cai XF, Chen K, et al. (2014). Sirtuin 1 regulates hepatitis B virus transcription and replication by targeting transcription factor AP-1. J Virol, 88:2442-2451.

[25] Dong SY, Guo YJ, Feng Y, Cui XX, Kuo SH, Liu T, et al. (2016). The epigenetic regulation of HIF-1alpha by SIRT1 in MPP $(+)$ treated SH-SY5Y cells. Biochem Biophys Res Commun, 470:453-459.

[26] Skoge RH, Dolle C, Ziegler M (2014). Regulation of SIRT2-dependent alpha-tubulin deacetylation by cellular NAD levels. DNA Repair (Amst), 23:33-38.

[27] Huang H, Zhang D, Wang Y, Perez-Neut M, Han Z, Zheng YG, et al. (2018). Lysine benzoylation is a histone mark regulated by SIRT2. Nat Commun, 9:3374.
[40] Benskey MJ, Perez RG, Manfredsson FP (2016). The contribution of alpha synuclein to neuronal survival and function - implications for Parkinson's disease. J Neurochem, 137:331-359.

[41] Olanow CW, Brundin P (2013). Parkinson's disease and alpha synuclein: is Parkinson's disease a prion-like disorder? Mov Disord, 28:31-40.

[42] Koronowski KB, Perez-Pinzon MA (2015). Sirt1 in cerebral ischemia. Brain Circ, 1:69-78.

[43] Zakhary SM, Ayubcha D, Dileo JN, Jose R, Leheste JR, Horowitz JM, et al. (2010). Distribution analysis of deacetylase SIRT1 in rodent and human nervous systems. Anat Rec (Hoboken), 293:1024-1032. 
[44] Quintas A, de Solis AJ, Diez-Guerra FJ, Carrascosa JM, Bogonez E (2012). Age-associated decrease of SIRT1 expression in rat hippocampus: prevention by late onset caloric restriction. Exp Gerontol, 47:198201.

[45] Pallas M, Pizarro JG, Gutierrez-Cuesta J, Crespo-Biel $\mathrm{N}$, Alvira D, Tajes M, et al. (2008). Modulation of SIRT1 expression in different neurodegenerative models and human pathologies. Neuroscience, 154:1388-1397.

[46] Singh P, Hanson PS, Morris CM (2017). SIRT1 ameliorates oxidative stress induced neural cell death and is down-regulated in Parkinson's disease. BMC Neurosci, 18:46.

[47] Ghavami S, Shojaei S, Yeganeh B, Ande SR, Jangamreddy JR, Mehrpour M, et al. (2014). Autophagy and apoptosis dysfunction in neurodegenerative disorders. Prog Neurobiol, 112:2449.

[48] Moulis M, Vindis C (2018). Autophagy in metabolic age-related human diseases. Cells, 7.

[49] Jiang W, Zhang X, Hao J, Shen J, Fang J, Dong W, et al. (2014). SIRT1 protects against apoptosis by promoting autophagy in degenerative human disc nucleus pulposus cells. Sci Rep, 4:7456.

[50] Miyazaki S, Kakutani K, Yurube T, Maeno K, Takada $\mathrm{T}$, Zhang Z, et al. (2015). Recombinant human SIRT1 protects against nutrient deprivation-induced mitochondrial apoptosis through autophagy induction in human intervertebral disc nucleus pulposus cells. Arthritis Res Ther, 17:253.

[51] Jeong JK, Moon MH, Lee YJ, Seol JW, Park SY (2013). Autophagy induced by the class III histone deacetylase Sirt1 prevents prion peptide neurotoxicity. Neurobiol Aging, 34:146-156.

[52] Wu Y, Li X, Zhu JX, Xie W, Le W, Fan Z, et al. (2011). Resveratrol-activated AMPK/SIRT1/autophagy in cellular models of Parkinson's disease. Neurosignals, 19:163-174.

[53] Guo YJ, Dong SY, Cui XX, Feng Y, Liu T, Yin M, et al. (2016). Resveratrol alleviates MPTP-induced motor impairments and pathological changes by autophagic degradation of alpha-synuclein via SIRT1deacetylated LC3. Mol Nutr Food Res, 60:2161-2175.

[54] Li SJ, Liu CH, Chang CW, Chu HP, Chen KJ, Mersmann HJ, et al. (2015). Development of a dietaryinduced metabolic syndrome model using miniature pigs involvement of AMPK and SIRT1. Eur J Clin Invest, 45:70-80.

[55] Lan F, Cacicedo JM, Ruderman N, Ido Y (2008). SIRT1 modulation of the acetylation status, cytosolic localization, and activity of LKB1. Possible role in AMP-activated protein kinase activation. J Biol Chem, 283:27628-27635.

[56] Maiese K (2016). Targeting molecules to medicine with mTOR, autophagy and neurodegenerative disorders. Br J Clin Pharmacol, 82:1245-1266.

[57] Feng Y, Liu T, Dong SY, Guo YJ, Jankovic J, Xu H, et al. (2015). Rotenone affects p53 transcriptional activity and apoptosis via targeting SIRT1 and H3K9 acetylation in SH-SY5Y cells. J Neurochem, 134:668676.

[58] Wang P, Guan YF, Du H, Zhai QW, Su DF, Miao CY (2012). Induction of autophagy contributes to the neuroprotection of nicotinamide phosphoribosyltransferase in cerebral ischemia. Autophagy, 8:77-87.

[59] Banreti A, Sass M, Graba Y (2013). The emerging role of acetylation in the regulation of autophagy. Autophagy, 9:819-829.

[60] Maiese K (2017). Forkhead transcription factors: formulating a FOXO target for cognitive loss. Curr Neurovasc Res, 14:415-420.

[61] Elbaz EM, Senousy MA, El-Tanbouly DM, Sayed RH (2018). Neuroprotective effect of linagliptin against cuprizone-induced demyelination and behavioural dysfunction in mice: a pivotal role of AMPK/SIRT1 and JAK2/STAT3/NF-kappaB signalling pathway modulation. Toxicol Appl Pharmacol, 352:153-161.

[62] Yang SR, Wright J, Bauter M, Seweryniak K, Kode A, Rahman I (2007). Sirtuin regulates cigarette smokeinduced proinflammatory mediator release via RelA/p65 NF-kappaB in macrophages in vitro and in rat lungs in vivo: implications for chronic inflammation and aging. Am J Physiol Lung Cell Mol Physiol, 292:L567-576.

[63] Kubota H (2009). Quality control against misfolded proteins in the cytosol: a network for cell survival. J Biochem, 146:609-616.

[64] Rodriguez L, Marano MM, Tandon A (2018). Import and export of misfolded alpha-synuclein. Front Neurosci, 12:344.

[65] Jacob P, Hirt H, Bendahmane A (2017). The heatshock protein/chaperone network and multiple stress resistance. Plant Biotechnol J, 15:405-414.

[66] Huang C, Wu J, Xu L, Wang J, Chen Z, Yang R (2018). Regulation of HSF1 protein stabilization: an updated review. Eur J Pharmacol, 822:69-77.

[67] Wang N, Zhang F, Yang L, Zou J, Wang H, Liu K, et al. (2017). Resveratrol protects against L-arginineinduced acute necrotizing pancreatitis in mice by enhancing SIRT1-mediated deacetylation of p53 and heat shock factor 1. Int J Mol Med, 40:427-437.

[68] Zelin E, Freeman BC (2015). Lysine deacetylases regulate the heat shock response including the ageassociated impairment of HSF1. J Mol Biol, 427:16441654.

[69] Raynes R, Leckey BD, Jr., Nguyen K, Westerheide SD (2012). Heat shock and caloric restriction have a synergistic effect on the heat shock response in a sir2.1-dependent manner in Caenorhabditis elegans. J Biol Chem, 287:29045-29053.

[70] Westerheide SD, Anckar J, Stevens SM, Jr., Sistonen L, Morimoto RI (2009). Stress-inducible regulation of heat shock factor 1 by the deacetylase SIRT1. Science, 323:1063-1066.

[71] Wang H, Dong X, Liu Z, Zhu S, Liu H, Fan W, et al. (2018). Resveratrol suppresses rotenone-induced neurotoxicity through activation of SIRT1/Akt1 signaling pathway. Anat Rec (Hoboken), 301:11151125 . 
[72] Liu T, Ma X, Ouyang T, Chen H, Lin J, Liu J, et al. (2018). SIRT1 reverses senescence via enhancing autophagy and attenuates oxidative stress-induced apoptosis through promoting p53 degradation. Int $\mathrm{J}$ Biol Macromol, 117:225-234.

[73] Zhang W, Wu H, Yang M, Ye S, Li L, Zhang H, et al. (2016). SIRT1 inhibition impairs non-homologous end joining DNA damage repair by increasing $\mathrm{Ku} 70$ acetylation in chronic myeloid leukemia cells. Oncotarget, 7:13538-13550.

[74] Yu W, Li L, Wang G, Zhang W, Xu J, Liang A (2018). KU70 inhibition impairs both non-homologous end joining and homologous recombination DNA damage repair through SHP-1 induced dephosphorylation of SIRT1 in T-cell acute lymphoblastic leukemia (T-ALL) [corrected]. Cell Physiol Biochem, 49:2111-2123.

[75] Anekonda TS, Adamus G (2008). Resveratrol prevents antibody-induced apoptotic death of retinal cells through upregulation of Sirt1 and Ku70. BMC Res Notes, 1:122.

[76] Ortiz GG, Pacheco Moises FP, Mireles-Ramirez M, Flores-Alvarado LJ, Gonzalez-Usigli H, SanchezGonzalez VJ, et al. (2017). Oxidative stress: love and hate history in central nervous system. Adv Protein Chem Struct Biol, 108:1-31.

[77] Lv J, Jiang S, Yang Z, Hu W, Wang Z, Li T, et al. (2018). PGC-1alpha sparks the fire of neuroprotection against neurodegenerative disorders. Ageing Res Rev, 44:8-21.

[78] Uldry M, Yang W, St-Pierre J, Lin J, Seale P, Spiegelman BM (2006). Complementary action of the PGC-1 coactivators in mitochondrial biogenesis and brown fat differentiation. Cell Metab, 3:333-341.

[79] Lerin C, Rodgers JT, Kalume DE, Kim SH, Pandey A, Puigserver P (2006). GCN5 acetyltransferase complex controls glucose metabolism through transcriptional repression of PGC-1alpha. Cell Metab, 3:429-438.

[80] Gerhart-Hines Z, Rodgers JT, Bare O, Lerin C, Kim SH, Mostoslavsky R, et al. (2007). Metabolic control of muscle mitochondrial function and fatty acid oxidation through SIRT1/PGC-1alpha. EMBO J, 26:1913-1923.

[81] Kaur K, Gill JS, Bansal PK, Deshmukh R (2017). Neuroinflammation - a major cause for striatal dopaminergic degeneration in Parkinson's disease. $\mathrm{J}$ Neurol Sci, 381:308-314

[82] Wang Q, Liu Y, Zhou J (2015). Neuroinflammation in Parkinson's disease and its potential as therapeutic target. Transl Neurodegener, 4:19.

[83] Holmes S, Singh M, Su C, Cunningham RL (2016). Effects of oxidative stress and testosterone on proinflammatory signaling in a female rat dopaminergic neuronal cell line. Endocrinology, 157:2824-2835.

[84] Wee Yong V (2010). Inflammation in neurological disorders: a help or a hindrance? Neuroscientist, 16:408-420.

[85] Leszek J, Barreto GE, Gasiorowski K, Koutsouraki E, Avila-Rodrigues M, Aliev G (2016). Inflammatory mechanisms and oxidative stress as key factors responsible for progression of neurodegeneration: role of brain innate immune system. CNS Neurol Disord Drug Targets, 15:329-336.

[86] Ye J, Liu Z, Wei J, Lu L, Huang Y, Luo L, et al. (2013). Protective effect of SIRT1 on toxicity of microglialderived factors induced by LPS to PC12 cells via the p53-caspase-3-dependent apoptotic pathway. Neurosci Lett, 553:72-77.

[87] Cho SH, Chen JA, Sayed F, Ward ME, Gao F, Nguyen TA, et al. (2015). SIRT1 deficiency in microglia contributes to cognitive decline in aging and neurodegeneration via epigenetic regulation of IL1beta. J Neurosci, 35:807-818.

[88] Bi XL, Yang JY, Dong YX, Wang JM, Cui YH, Ikeshima T, et al. (2005). Resveratrol inhibits nitric oxide and TNF-alpha production by lipopolysaccharide-activated microglia. Int Immunopharmacol, 5:185-193.

[89] Zhang A, Wang H, Qin X, Pang S, Yan B (2012). Genetic analysis of SIRT1 gene promoter in sporadic Parkinson's disease. Biochem Biophys Res Commun, 422:693-696.

[90] Jesus S, Gomez-Garre P, Carrillo F, Caceres-Redondo MT, Huertas-Fernandez I, Bernal-Bernal I, et al. (2013). Genetic association of sirtuin genes and Parkinson's disease. J Neurol, 260:2237-2241.

[91] Yang XD, Qian YW, Xu SQ, Wan DY, Sun FH, Chen SD, et al. (2018). Expression of the gene coding for PGC-1alpha in peripheral blood leukocytes and related gene variants in patients with Parkinson's disease. Parkinsonism Relat Disord, 51:30-35.

[92] Hohman TJ, Bush WS, Jiang L, Brown-Gentry KD, Torstenson ES, Dudek SM, et al. (2016). Discovery of gene-gene interactions across multiple independent data sets of late onset Alzheimer disease from the Alzheimer disease genetics consortium. Neurobiol Aging, 38:141-150.

[93] Kilic U, Gok O, Erenberk U, Dundaroz MR, Torun E, Kucukardali Y, et al. (2015). A remarkable age-related increase in SIRT1 protein expression against oxidative stress in elderly: SIRT1 gene variants and longevity in human. PLoS One, 10:e0117954.

[94] Wang Q, Xu J, Rottinghaus GE, Simonyi A, Lubahn D, Sun GY, et al. (2002). Resveratrol protects against global cerebral ischemic injury in gerbils. Brain Res, 958:439-447.

[95] Robb EL, Stuart JA (2010). trans-Resveratrol as a neuroprotectant. Molecules, 15:1196-1212.

[96] Albani D, Polito L, Batelli S, De Mauro S, Fracasso C, Martelli G, et al. (2009). The SIRT1 activator resveratrol protects SK-N-BE cells from oxidative stress and against toxicity caused by alpha-synuclein or amyloid-beta (1-42) peptide. J Neurochem, 110:1445-1456.

[97] Lee MK, Kang SJ, Poncz M, Song KJ, Park KS (2007). Resveratrol protects SH-SY5Y neuroblastoma cells from apoptosis induced by dopamine. Exp Mol Med, 39:376-384

[98] Alvira D, Yeste-Velasco M, Folch J, Verdaguer E, Canudas AM, Pallas M, et al. (2007). Comparative analysis of the effects of resveratrol in two apoptotic 
models: inhibition of complex I and potassium deprivation in cerebellar neurons. Neuroscience, 147:746-756.

[99] Bournival J, Quessy P, Martinoli MG (2009). Protective effects of resveratrol and quercetin against MPP+ -induced oxidative stress act by modulating markers of apoptotic death in dopaminergic neurons. Cell Mol Neurobiol, 29:1169-1180.

[100] Lin TK, Chen SD, Chuang YC, Lin HY, Huang CR, Chuang JH, et al. (2014). Resveratrol partially prevents rotenone-induced neurotoxicity in dopaminergic SH-SY5Y cells through induction of heme oxygenase-1 dependent autophagy. Int J Mol Sci, 15:1625-1646.

[101] Anandhan A, Tamilselvam K, Vijayraja D, Ashokkumar N, Rajasankar S, Manivasagam T (2010). Resveratrol attenuates oxidative stress and improves behaviour in 1 -methyl-4-phenyl-1,2,3,6tetrahydropyridine (MPTP) challenged mice. Ann Neurosci, 17:113-119.

[102] Blanchet J, Longpre F, Bureau G, Morissette M, DiPaolo T, Bronchti G, et al. (2008). Resveratrol, a red wine polyphenol, protects dopaminergic neurons in MPTP-treated mice. Prog Neuropsychopharmacol Biol Psychiatry, 32:1243-1250.

[103] Lu KT, Ko MC, Chen BY, Huang JC, Hsieh CW, Lee $\mathrm{MC}$, et al. (2008). Neuroprotective effects of resveratrol on MPTP-induced neuron loss mediated by free radical scavenging. J Agric Food Chem, 56:69106913.

[104] Wang Y, Xu H, Fu Q, Ma R, Xiang J (2011). Protective effect of resveratrol derived from Polygonum cuspidatum and its liposomal form on nigral cells in parkinsonian rats. J Neurol Sci, 304:29-34.

[105] Ferretta A, Gaballo A, Tanzarella P, Piccoli C, Capitanio N, Nico B, et al. (2014). Effect of resveratrol on mitochondrial function: implications in parkin-associated familiar Parkinson's disease. Biochim Biophys Acta, 1842:902-915.

[106] Smoliga JM, Vang O, Baur JA (2012). Challenges of translating basic research into therapeutics: resveratrol as an example. J Gerontol A Biol Sci Med Sci, 67:158167.

[107] Howitz KT, Bitterman KJ, Cohen HY, Lamming DW, Lavu S, Wood JG, et al. (2003). Small molecule activators of sirtuins extend Saccharomyces cerevisiae lifespan. Nature, 425:191-196.

[108] Milne JC, Lambert PD, Schenk S, Carney DP, Smith JJ, Gagne DJ, et al. (2007). Small molecule activators of SIRT1 as therapeutics for the treatment of type 2 diabetes. Nature, 450:712-716.

[109] Kasiotis KM, Pratsinis H, Kletsas D, Haroutounian SA (2013). Resveratrol and related stilbenes: their antiaging and anti-angiogenic properties. Food Chem Toxicol, 61:112-120.

[110] Riviere C, Pawlus AD, Merillon JM (2012). Natural stilbenoids: distribution in the plant kingdom and chemotaxonomic interest in Vitaceae. Nat Prod Rep, 29:1317-1333.

[111] Temsamani H, Krisa S, Decossas-Mendoza M,
Lambert O, Mérillon JM, Richard T (2016). Piceatannol and other wine stilbenes: a pool of inhibitors against $\alpha$-synuclein aggregation and cytotoxicity. Nutrients, 8 .

[112] Nishida K, Matsushita T, Takayama K, Tanaka T, Miyaji N, Ibaraki K, et al. (2018). Intraperitoneal injection of the SIRT1 activator SRT1720 attenuates the progression of experimental osteoarthritis in mice. Bone Joint Res, 7:252-262.

[113] Opal SM, Ellis JL, Suri V, Freudenberg JM, Vlasuk GP, Li Y, et al. (2016). Pharmacological SIRT1 activation improves mortality and markedly alters transcriptional profiles that accompany experimental sepsis. Shock, 45:411-418

[114] Mitchell SJ, Martin-Montalvo A, Mercken EM, Palacios HH, Ward TM, Abulwerdi G, et al. (2014). The SIRT1 activator SRT1720 extends lifespan and improves health of mice fed a standard diet. Cell Rep, 6:836-843.

[115] Miranda MX, van Tits LJ, Lohmann C, Arsiwala T, Winnik S, Tailleux A, et al. (2015). The SIRT1 activator SRT3025 provides atheroprotection in Apoe/- mice by reducing hepatic Pcsk9 secretion and enhancing LDLR expression. Eur Heart J, 36:51-59.

[116] Graff J, Kahn M, Samiei A, Gao J, Ota KT, Rei D, et al. (2013). A dietary regimen of caloric restriction or pharmacological activation of SIRT1 to delay the onset of neurodegeneration. J Neurosci, 33:8951-8960.

[117] Liu P, Feng T, Zuo X, Wang X, Luo J, Li N, et al. (2018). A novel SIRT1 activator E6155 improves insulin sensitivity in type 2 diabetic KKAy mice. Biochem Biophys Res Commun, 498:633-639.

[118] Zordoky BN, Robertson IM, Dyck JR (2015). Preclinical and clinical evidence for the role of resveratrol in the treatment of cardiovascular diseases. Biochim Biophys Acta, 1852:1155-1177.

[119] Agarwal B, Campen MJ, Channell MM, Wherry SJ, Varamini B, Davis JG, et al. (2013). Resveratrol for primary prevention of atherosclerosis: clinical trial evidence for improved gene expression in vascular endothelium. Int J Cardiol, 166:246-248.

[120] Seyyedebrahimi S, Khodabandehloo H, Nasli Esfahani E, Meshkani R (2018). The effects of resveratrol on markers of oxidative stress in patients with type 2 diabetes: a randomized, double-blind, placebo-controlled clinical trial. Acta Diabetol, 55:341-353.

[121] Pennisi M, Bertino G, Gagliano C, Malaguarnera M, Bella R, Borzi AM, et al. (2017). Resveratrol in hepatitis $\mathrm{C}$ patients treated with pegylated-interferonalpha- $2 \mathrm{~b}$ and ribavirin reduces sleep disturbance. Nutrients, 9.

[122] Moussa C, Hebron M, Huang X, Ahn J, Rissman RA, Aisen PS, et al. (2017). Resveratrol regulates neuroinflammation and induces adaptive immunity in Alzheimer's disease. J Neuroinflammation, 14:1.

[123] Banaszewska B, Wrotynska-Barczynska J, Spaczynski RZ, Pawelczyk L, Duleba AJ (2016). Effects of resveratrol on polycystic ovary syndrome: a doubleblind, randomized, placebo-controlled trial. J Clin 
Endocrinol Metab, 101:4322-4328.

[124] Baksi A, Kraydashenko O, Zalevkaya A, Stets R, Elliott P, Haddad J, et al. (2014). A phase II, randomized, placebo-controlled, double-blind, multidose study of SRT2104, a SIRT1 activator, in subjects with type 2 diabetes. Br J Clin Pharmacol, 78:69-77.

[125] Sands BE, Joshi S, Haddad J, Freudenberg JM, Oommen DE, Hoffmann E, et al. (2016). Assessing colonic exposure, safety, and clinical activity of SRT2104, a novel oral SIRT1 activator, in patients with mild to moderate ulcerative colitis. Inflamm Bowel Dis, 22:607-614.

[126] Krueger JG, Suarez-Farinas M, Cueto I, Khacherian A, Matheson R, Parish LC, et al. (2015). A randomized, placebo-controlled study of SRT2104, a SIRT1 activator, in patients with moderate to severe psoriasis. PLoS One, 10:e0142081.

[127] Venkatasubramanian S, Noh RM, Daga S, Langrish JP, Joshi NV, Mills NL, et al. (2013). Cardiovascular effects of a novel SIRT1 activator, SRT2104, in otherwise healthy cigarette smokers. J Am Heart Assoc, 2:e000042.

[128] Voorhees JR, Remy MT, Cintron-Perez CJ, El Rassi E, Khan MZ, Dutca LM, et al. (2018). (-)-P7C3-S243 protects a rat model of Alzheimer's disease from neuropsychiatric deficits and neurodegeneration without altering amyloid deposition or reactive glia. Biol Psychiatry, 84:488-498.

[129] Tesla R, Wolf HP, Xu P, Drawbridge J, Estill SJ, Huntington P, et al. (2012). Neuroprotective efficacy of aminopropyl carbazoles in a mouse model of amyotrophic lateral sclerosis. Proc Natl Acad Sci U S A, 109:17016-17021.

[130] Blaya MO, Wasserman JM, Pieper AA, Sick TJ, Bramlett HM, Dietrich WD (2018). Neurotherapeutic Capacity of P7C3 Agents for the Treatment of Traumatic Brain Injury. Neuropharmacology.

[131] Zhang LQ, Nsumu M, Huang P, Heruth DP, Riordan SM, Shortt K, et al. (2018). Novel protective role of nicotinamide phosphoribosyltransferase in acetaminophen-induced acute liver injury in mice. Am J Pathol, 188:1640-1652.

[132] Oku H, Morishita S, Horie T, Nishikawa Y, Kida T, Mimura M, et al. (2017). Protective effect of P7C3 on retinal ganglion cells from optic nerve injury. Jpn J Ophthalmol, 61:195-203.

[133] Wang SN, Xu TY, Wang X, Guan YF, Zhang SL, Wang $\mathrm{P}$, et al. (2016). Neuroprotective efficacy of an aminopropyl carbazole derivative P7C3-A20 in ischemic stroke. CNS Neurosci Ther, 22:782-788.

[134] Rajman L, Chwalek K, Sinclair DA (2018). Therapeutic potential of NAD-boosting molecules: the in vivo evidence. Cell Metab, 27:529-547.

[135] Anderson RM, Bitterman KJ, Wood JG, Medvedik O, Sinclair DA (2003). Nicotinamide and PNC1 govern lifespan extension by calorie restriction in Saccharomyces cerevisiae. Nature, 423:181-185.

[136] Gallo CM, Smith DL, Jr., Smith JS (2004). Nicotinamide clearance by Pnc1 directly regulates Sir2-mediated silencing and longevity. Mol Cell Biol,
24:1301-1312.

[137] Yaku K, Okabe K, Nakagawa T (2018). NAD metabolism: implications in aging and longevity. Ageing Res Rev, 47:1-17.

[138] Zou XD, Guo SQ, Hu ZW, Li WL (2016). NAMPT protects against 6-hydroxydopamine-induced neurotoxicity in PC12 cells through modulating SIRT1 activity. Mol Med Rep, 13:4058-4064.

[139] Wang G, Han T, Nijhawan D, Theodoropoulos P, Naidoo J, Yadavalli S, et al. (2014). P7C3 neuroprotective chemicals function by activating the rate-limiting enzyme in NAD salvage. Cell, 158:13241334.

[140] De Jesus-Cortes H, Xu P, Drawbridge J, Estill SJ, Huntington P, Tran S, et al. (2012). Neuroprotective efficacy of aminopropyl carbazoles in a mouse model of Parkinson disease. Proc Natl Acad Sci U S A, 109:17010-17015.

[141] Baur JA, Pearson KJ, Price NL, Jamieson HA, Lerin C, Kalra A, et al. (2006). Resveratrol improves health and survival of mice on a high-calorie diet. Nature, 444:337-342.

[142] Hubbard BP, Gomes AP, Dai H, Li J, Case AW, Considine T, et al. (2013). Evidence for a common mechanism of SIRT1 regulation by allosteric activators. Science, 339:1216-1219.

[143] Pacholec M, Bleasdale JE, Chrunyk B, Cunningham D, Flynn D, Garofalo RS, et al. (2010). SRT1720, SRT2183, SRT1460, and resveratrol are not direct activators of SIRT1. J Biol Chem, 285:8340-8351.

[144] Santos D, Mahoney JR, Allali G, Verghese J (2017). Physical activity in older adults with mild parkinsonian signs: a cohort study. J Gerontol A Biol Sci Med Sci, 73:1682-1687.

[145] Hou L, Chen W, Liu X, Qiao D, Zhou FM (2017). Exercise-induced neuroprotection of the nigrostriatal dopamine system in Parkinson's disease. Front Aging Neurosci, 9:358.

[146] Tuon T, Souza PS, Santos MF, Pereira FT, Pedroso GS, Luciano TF, et al. (2015). Physical training regulates mitochondrial parameters and neuroinflammatory mechanisms in an experimental model of Parkinson's disease. Oxid Med Cell Longev, 2015:261809.

[147] Munoz A, Correa CL, Lopez-Lopez A, Costa-Besada MA, Diaz-Ruiz C, Labandeira-Garcia JL (2018). Physical exercise improves aging-related changes in angiotensin, IGF-1, SIRT 1, SIRT3 and VEGF in the substantia nigra. J Gerontol A Biol Sci Med Sci, 73:1594-1601.

[148] Vaziri H, Dessain SK, Ng Eaton E, Imai SI, Frye RA, Pandita TK, et al. (2001). hSIR2(SIRT1) functions as an NAD-dependent p53 deacetylase. Cell, 107:149159.

[149] Cohen HY, Miller C, Bitterman KJ, Wall NR, Hekking B, Kessler B, et al. (2004). Calorie restriction promotes mammalian cell survival by inducing the SIRT1 deacetylase. Science, 305:390-392.

[150] Roth M, Wang Z, Chen WY (2016). SIRT1 and LSD1 competitively regulate KU70 functions in DNA repair and mutation acquisition in cancer cells. Oncotarget, 
7:50195-50214.

[151] Wang R, Li JJ, Diao S, Kwak YD, Liu L, Zhi L, et al. (2013). Metabolic stress modulates Alzheimer's betasecretase gene transcription via SIRT1-PPARgammaPGC-1 in neurons. Cell Metab, 17:685-694.

[152] Qiang L, Wang L, Kon N, Zhao W, Lee S, Zhang Y, et al. (2012). Brown remodeling of white adipose tissue by SirT1-dependent deacetylation of Ppargamma. Cell, 150:620-632.

[153] Julien C, Tremblay C, Emond V, Lebbadi M, Salem N, Jr., Bennett DA, et al. (2009). Sirtuin 1 reduction parallels the accumulation of tau in Alzheimer disease. J Neuropathol Exp Neurol, 68:48-58.

[154] Min SW, Sohn PD, Li Y, Devidze N, Johnson JR, Krogan NJ, et al. (2018). SIRT1 deacetylates Tau and reduces pathogenic tau spread in a mouse model of tauopathy. J Neurosci, 38:3680-3688.

[155] Jeong H, Cohen DE, Cui L, Supinski A, Savas JN, Mazzulli JR, et al. (2011). Sirt1 mediates neuroprotection from mutant huntingtin by activation of the TORC1 and CREB transcriptional pathway. Nat Med, 18:159-165.

[156] Grewal AK, Singh N, Singh TG (2019). Effects of resveratrol postconditioning on cerebral ischemia in mice: role of the sirtuin-1 pathway. Can J Physiol Pharmacol, 97:1094-1101.

[157] Perrini S, Porro S, Nigro P, Cignarelli A, Caccioppoli C, Genchi VA, et al. (2019). Reduced SIRT1 and SIRT2 expression promotes adipogenesis of human visceral adipose stem cells and associates with accumulation of visceral fat in human obesity. Int $\mathbf{J}$ Obes (Lond) , 44:307-319.

[158] Wu SY, Liang J, Yang BC, Leung PS (2019). SIRT1 activation promotes beta-cell regeneration by activating endocrine progenitor cells via AMPK signaling-mediated fatty acid oxidation. Stem Cells, 37:1416-1428. 